\title{
Gamificação e ensino do léxico na aprendizagem da língua portuguesa
}

Geraldo José Rodrigues Liska*

\section{Resumo}

Seguindo os pressupostos de Gee (2003, 2004, 2005 e 2014), defendemos que os jogos digitais podem se tornar um poderoso recurso de ensino de uma língua e, neste trabalho, trataremos do português como língua materna e do ensino de palavras e sentidos. Primeiramente, tratamos de como é o ensino do léxico na sala de aula de educação básica, aqui englobando palavras e sentidos. Em seguida, tratamos da utilização dos jogos digitais como ferramentas de ensino. Selecionamos alguns jogos e expusemos seus aspectos técnicos e mecanismos, como layout, interatividade, diversão e jogabilidade. Realizamos uma relação entre esses aspectos aos elementos que os caracterizam como ferramenta educativa. Com a finalidade de nos aprofundar sobre o assunto, procuramos e testamos jogos digitais gratuitos que se propõem a ensinar palavras e sentidos e os analisamos, relacionando fatores que contribuem para o aprofundamento de uma dimensão mais importante do estudo do léxico e da relação entre a língua e a existência do falante ao contrário de aspectos formais secundários de ordem meramente sistêmica. De todos os games analisados, "Scribblenauts" permite ao jogador utilizar a língua para se expressar e partilhar informações, experiências, ideias e sentimentos em diferentes contextos e produzir sentidos que levem à resolução dos desafios propostos e aprimorar os conhecimentos grafofônicos, ortográficos, lexicais, morfológicos e semânticos que operam nas análises linguísticas e semióticas necessárias à compreensão e à produção de linguagens, lembrando que essa habilidade precisa ser concomitantemente construída a partir do $1^{\circ}$ ano do Ensino Fundamental.

Palavras-chave: Jogos digitais. Gamificação. Ensino do léxico. Ensino de língua. Ensino de português.

\section{Introdução}

No estudo da língua, percebemos que ainda é comum a análise gramatical das palavras por meio de sua configuração morfológica e/ou função sintática. Ainda

\footnotetext{
Doutor em Estudos Linguísticos pela Universidade Federal de Minas Gerais. Secretário Executivo da Universidade Federal de Alfenas, MG. E-mail: geraldliska@ hotmail.com
}

Data de submissão: abr. 2019 - Data de aceite: jul. 2019 http://dx.doi.org/10.5335/rdes.v15i2.8695 
são incipientes as iniciativas, inclusive nos livros didáticos de português, em ressaltar a importância do significado, com todas as possibilidades que os diversos usos de uma palavra permitem, conforme evidenciamos em nossa pesquisa de mestrado (LISKA, 2013).

É comum vermos o foco na estrutura da palavra, por meio de nomeações e classificações, com atividades sobre circular substantivos, verbos e adjetivos de um texto, por exemplo, ou então sobre destacar afixos e radicais de uma lista de palavras e classificar as derivações em prefixais ou sufixais conforme os afixos destacados. Nesses casos, não se ressaltam os valores culturais e metafóricos que uma palavra pode carregar e é deixado de lado o comportamento sintático-semântico entre as palavras em relação, isso para encaixá-las em determinada classe somente pela sua estrutura.

As propostas curriculares de todas as esferas do governo, desde os Parâmetros Curriculares Nacionais (PCN) (BRASIL, 1998) até a Base Nacional Comum Curricular (BNCC) (BRASIL, 2017) procuram valorizar a produção do sentido, uma vez que isso é fundamental para o domínio da leitura e, consequentemente, da escrita, já que ler é uma atividade de atribuição de sentidos.

Pensando nessa atividade de atribuição de sentidos, este trabalho procura destacar o estudo da língua com a utilização de jogos digitais para o desen- volvimento da competência léxica. Para falarmos de ensino de léxico e significação, não há como analisar termos isolados, fora de um texto, de um contexto. Conforme Fregonezi (1994), a linguagem deixa de ser analisada nos limites do enunciado para englobar fatores relacionados à enunciação. $\mathrm{O}$ aluno expandirá seu acervo de palavras ao observar a relação entre elas em um contexto sociopragmático e cultural, quando estuda e pratica a sua língua na interação com o mundo que o cerca, num espaço/tempo de construção de significações que se desenvolvem com a realidade.

Procuramos jogos digitais gratuitos que se propõem a ensinar palavras e sentidos e os analisamos, relacionando fatores que contribuem para o aprofundamento de uma dimensão mais importante do estudo do léxico e da relação entre a língua e a existência do falante, ao contrário de aspectos formais secundários de ordem meramente sistêmica (como a classificação morfológica de uma palavra ou sua função sintática em uma frase).

\section{Ensino do léxico na educação básica}

Diferentemente da situação sobre o ensino do léxico na escola, evidenciado na dissertação de mestrado (LISKA, 2013), defendemos que o léxico é a primeira etapa do percurso científico do ser humano com o universo. Automaticamente, o ho- 
mem classifica, identifica semelhanças e discrimina traços distintivos dos seres e objetos. Dessa forma, podemos perceber claramente que a gramática, aqui entendida como um conjunto de regras, é criada a partir do léxico funcional, isto é, do léxico aplicado, em uso, na língua real, pois é aí que cada unidade lexical ganha as propriedades que permitem a construção de quase todo o restante das regras gramaticais.

O conhecimento referente ao léxico, ao conhecimento das palavras, é crucial, principalmente nos estágios iniciais de aprendizagem de qualquer língua. Mesmo com essa afirmação, quando se trata do estudo da palavra, vemos, com frequência em livros didáticos de português, textos propostos para atividades de compreensão e interpretação leitora seguidos de um quadro denominado de "vocabulário", repleto de palavras e seus sentidos possíveis naquele texto a partir de um cenário previamente estabelecido pelo autor, sem a chance de o aluno ter qualquer esforço cognitivo para inferenciar o sentido dessas palavras e desprezando-se o fato de que a leitura é sempre intermediada pela construção socio-histórica e cultural do leitor.

$\mathrm{Ou}$, ainda, quando esses sentidos não eram fornecidos, orientava-se o aluno a procurá-los no dicionário, muitas vezes, sem a devida instrução de como fazê-lo, uma vez que o próprio professor também não era (ou ainda não é) orientado a tra- balhar com o dicionário, problema que remonta ao período de sua formação, nos cursos de licenciatura, e que deveria ser solucionado, pelo menos, na formação dos professores dos cursos de Letras e de Pedagogia.

De maneira ampla, o desenvolvimento da competência lexical deve proporcionar ao aluno a oportunidade de expandir seu acervo lexical e de perceber os vários sentidos possíveis que as palavras podem apresentar, seja na relação entre elas dentro ou fora de um enunciado. Assim, podemos dizer que a inferência do significado lexical está intimamente ligada ao conhecimento preexistente, a nível linguístico e enciclopédico, dos itens lexicais que rodeiam determinada palavra e/ou da composição morfológica e possibilidades sintáticas e semânticas de uso desta. Conforme Laufer (1986), não há fluência sem uma base sólida de vocabulário; nenhum insumo será abrangente e relevante se o léxico do aprendiz for pobre.

Mas esse pensamento nem sempre foi assim. Maiguascha (1993 apud DELL'ISOLA, 2005), em suas pesquisas ao longo de vinte anos (1970-90), afirma que até o final da década de 1980 não havia necessidade de se ensinar explicitamente palavras e seus significados, pois acreditava-se que os aprendizes compreenderiam o vocabulário indiretamente em atividades comunicativas ou gramaticais ou quando liam. 
Além disso, a atenção ao léxico era pouca. O Brasil recebeu grandes contribuições da lexicóloga Maria Tereza Camargo Biderman nessa área. Para ela, "o vocabulário exerce um papel crucial na veiculação do significado, que é, afinal de contas, o objeto da comunicação linguística" (1996, p. 27). Assim, qualquer informação tem origem no léxico, combinando signos linguísticos, transformando-os em enunciados e integrando-os à realidade. Hoje, sabemos que o léxico é o meio primordial ao qual os sentidos culturalmente construídos ao longo da existência do falante são associados no ato comunicativo. Isso agrava a questão, pois demonstra que o falante não apenas tem que conhecer o léxico de sua língua, mas, também, precisa dominar o processo pelo qual se atribui sentido às unidades desse léxico, de maneira adequada, em cada construção cotidiana de fala ou escrita.

Para Richards (1976), ensinar léxico, isto é, permitir ao aluno o conhecimento das palavras e do vocabulário, implica expandir o vocabulário ao longo da vida; conhecer a frequência e a colocação das palavras; conhecer as limitações de uso impostas às palavras; reconhecer o comportamento sintático das palavras; compreender formas subjacentes e derivacionais (regras de formação) das palavras; saber estabelecer associações entre as palavras numa relação intralinguística; conhecer o valor semântico das palavras, seus traços e suas restrições semânticas de uso; e conhecer as várias possibilidades de uso das palavras por meio da sua multissignificação.

Na BNCC (BRASIL, 2017), documento norteador mais recente em âmbito nacional para a educação básica, os conhecimentos grafofônicos, ortográficos, lexicais, morfológicos, sintáticos, textuais, discursivos, sociolinguísticos e semióticos que operam nas análises linguísticas e semióticas necessárias à compreensão e à produção de linguagens precisam ser, concomitantemente, construídos durante o Ensino Fundamental.

\section{Jogos digitais e ensino}

As escolas atuais enfrentam grandes problemas em torno da motivação e do envolvimento dos alunos. A gamificação, ou a incorporação de elementos de um jogo ${ }^{1}$, como como estética, mecânica e dinâmica, em outros contextos não relacionados a jogos (KAPP, 2012), passou a oferecer uma oportunidade para ajudar as escolas a resolver esses problemas difíceis.

Para Leffa, Bohn, Damasceno, Marzari (2012), os jogos digitais são uma prática social caracterizada pelo uso intensivo da língua, envolvem o jogador por imersão, trazendo-o para dentro do jogo, e exige dele conhecimento para atingir os desafios colocados. Assim, acredita-se que uma sessão de um game produz um impacto permanente no jogador, de modo mais intenso do que um livro, uma música 
ou um filme, visto que há um envolvimento físico maior do sujeito.

$\mathrm{O}$ valor de entretenimento de um jogo digital, por exemplo, segundo Leffa, Bohn, Damasceno, Marzari (2012), é mais importante para defini-lo como game do que seu valor educativo. O bom jogo eletrônico é aquele que vicia, não necessariamente aquele que ensina; um jogo pedagógico com ênfase no uso de recursos interativos, mas com baixo valor de entretenimento, ficaria na fronteira entre o game e o exercício didático.

Leffa Leffa, Bohn, Damasceno, Marzari (2012) apresenta algumas variáveis categóricas e contínuas que caracterizariam um game, podendo essas ser obrigatórias ou opcionais:

A) Categóricas (que não são medidas por uma escala de valor, mas por pertencer, ou não, a uma determinada categoria). Seriam elas:

(1) o algoritmo, que faz do videogame um evento interativo, sensível aos gestos do usuário, às vezes respondendo ao que ele faz, às vezes propondo ações novas;

(2) a ação física do jogador (alguns jogos que envolvem engajamento físico);

(3) o suporte eletrônico: a tela ou monitor, alto-falantes e inúmeros elementos gráficos que informam o andamento do jogo como cursores, botões e barras de rolagem, além de dispositi- vos de entrada como teclado, controles, mouse, joysticks, pedais, volantes, software e hardware, input e output etc.

B) Contínuas:

(1) ludicidade;

(2) interatividade e

(3) explicitação de valores.

Além dessas especifidades, Gee (2014) apresenta alguns princípios para a gamificação. Em resumo, espera-se que um design de jogo:

(1) determine um objetivo principal e sub-objetivos;

(2) ofereça tarefas claras e pequenas;

(3) apresente tarefas mais difíceis conforme a progressão no jogo;

(4) não permita que o jogador falhe logo no começo, para não desestimulá-lo;

(5) crie um desafio usando elementos de jogo e mecânica, considerando cada tipo de jogador;

(6) deixe que o jogador assuma o controle, mas não permita que eles se percam ou fiquem preso a ponto de desistir do jogo.

Um game para o ensino de língua não pode servir apenas para aprender um repertório de frases; ele deve ser necessário para aprender a encaixar as frases ao contexto, desde o corpo e seus movimentos nas interações, nas tentativas de pertencimento a novas comunidades, quer sejam virtuais, quer sejam reais. Mais do que aprender a 
falar e a escrever, o aluno, com o game, tem a possibilidade de aprender a ser, convivendo com diferentes identidades e explorando seus próprios avatares.

Diante dessas categorias e especificações, devemos ter atenção àquilo que se intitula "jogo digital" ou "game" e estão sendo usados em ensino de línguas apenas para mascarar atividades enfadonhas enquanto as torna ligeiramente menos enfadonhas.

Temos que tomar cuidado com atividades tradicionais travestidas como jogo, na tentativa de ensinar e divertir ao mesmo tempo: "esses exercícios animados vestem-se como games, mas estão despidos de qualquer coisa que lembre um jogo" (OSTERWEIL; LE, 2010, apud LEFFA; BOHN; DAMASCENO; MARZARI, 2012).

Assim, um exercício interativo em que o aluno responde a perguntas feitas pelo computador com feedback automático tem um algoritmo, um suporte eletrônico e a atividade do aluno, mas não seria considerado um game, pois não corresponderia às seis características esperadas no design de jogo detalhadas por Gee (2014).

Com a finalidade de nos aprofundar sobre o assunto, procuramos jogos digitais gratuitos que se propõem a ensinar palavras e sentidos e os analisamos, relacionando fatores que contribuem para o aprofundamento de uma dimensão mais importante do estudo do léxico e da relação entre a língua e a existência do falante ao contrário de aspectos formais secundários de ordem meramente sistêmica. Apresentaremos essa análise na seção seguinte.

\section{Exemplos de jogos digitais}

Figura 1 - Jogo dos substantivos

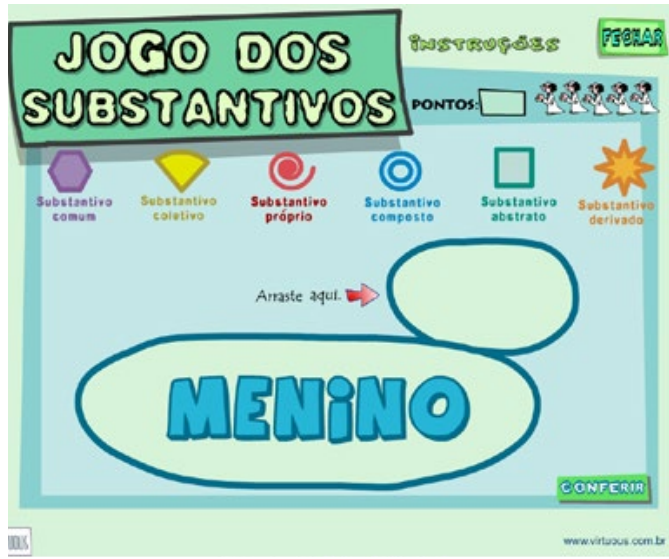

Fonte: JOGO DOS SUBSTANTIVOS, s. d.

Figura 2 - Jogo dos advérbios

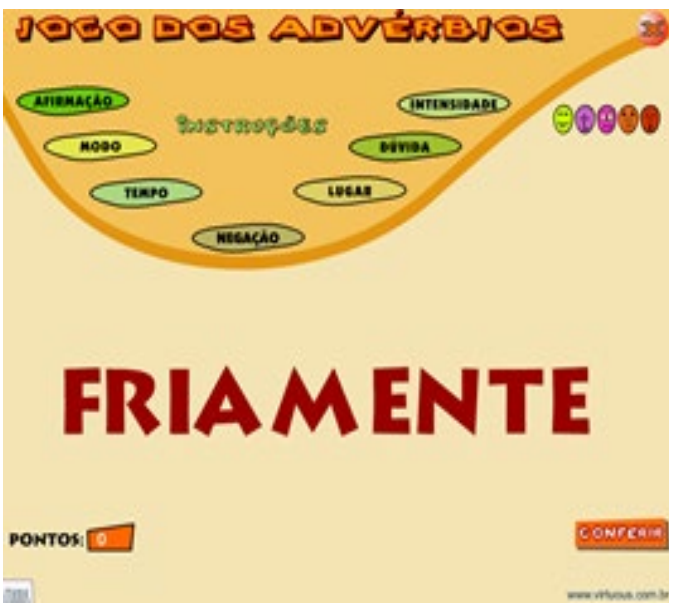

Fonte: JOGO DOS ADVÉRBIOS, s. d.

O "Jogo dos substantivos" (Figura 1) e o "Jogo dos advérbios" (Figura 2) se resumem a classificar uma palavra em 
foco, sendo ela um substantivo comum, abstrato, derivado... ou um advérbio de modo, tempo, lugar... Voltamos aqui a tratar de uma preocupação (muito comum nos livros didáticos de português e, como vimos, refletida nos jogos educativos) com a classificação e nomeação de palavras, em detrimento de compreender processos e fenômenos linguísticos.

Essa visão terminológica e enciclopedista trazida pelos livros didáticos de português priva $o$ aluno de se aprofundar em uma dimensão mais importante do estudo do léxico e da relação entre a língua e a existência do falante. Sabemos que a língua está em constante mudança, o que muitas vezes resulta num distanciamento entre o que se usa efetivamente e o que fixam as normas, mas elas são necessárias para o funcionamento da língua, o que não envolve um viés prescritivo, mas, sim, funcional, ao saber o porquê de determinada palavra estar inserida em um dado contexto, e não qual a sua classificação sintática ou morfológica, somente.

Figura 3 - Seguindo a lógica

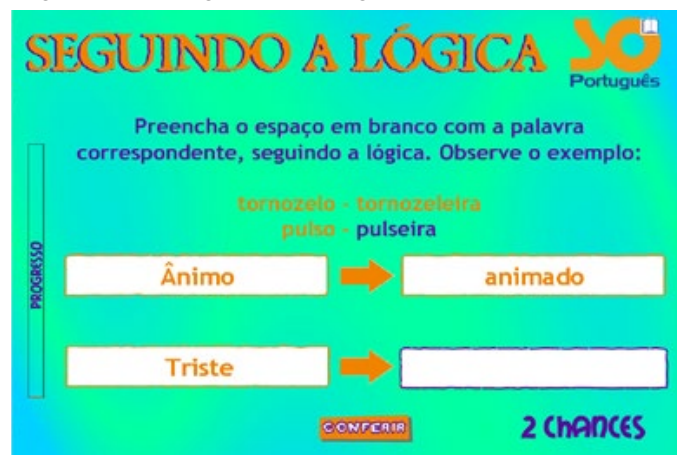

Fonte: SEGUINDO A LÓGICA, s. d.
Em outro jogo, "Seguindo a lógica" (Figura 3), pede-se para preencher o espaço em branco com a palavra correspondente, seguindo a lógica tornozelo/tornozeleira, pulso/pulseira. Isso privilegia um estudo voltado somente para a forma, sobrepondo o sentido das formações. Mais que reconhecer prefixos e sufixos produtivos na formação de palavras derivadas de substantivos, de adjetivos e de verbos, o aluno precisa saber utilizá-los para compreender palavras e para formar outras novas. Além disso, se nos atentarmos para o exemplo da lógica para respondermos "ânimo/animado, triste/?", a resposta deveria ser *tristado.

Figura 4 - Palavras complicadas

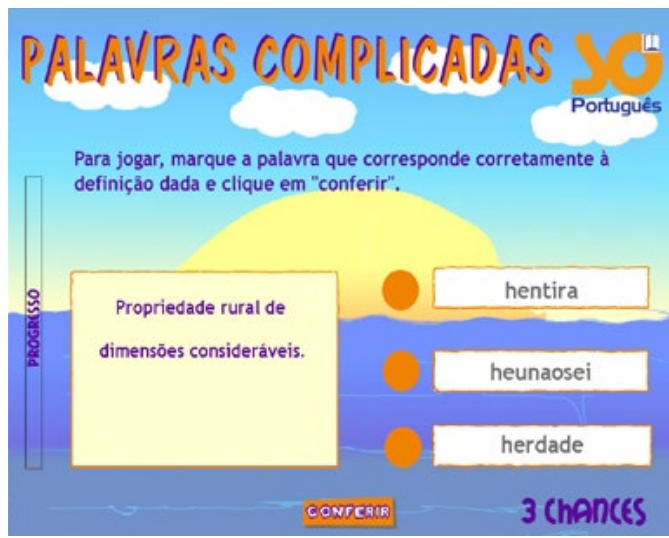

Fonte: PALAVRAS COMPLICADAS, s. d.

"Palavras complicadas" (Figura 4) se aproxima de um jogo de adivinhação. Seria interessante se o jogo apresentasse uma palavra em determinado contexto de uso para que essa adivinhação fosse realizada, por meio de estratégias de 
inferenciação, não ficando destinada a escolhas aleatórias. Conforme Dell'Isola (1991), o leitor estabelece elos lexicais e busca extratexto informações e conhecimentos adquiridos pela experiência de vida. Além disso, é comum, no dia a dia, fazermos uso do que conhecemos para inferir o que não conhecemos (princípio que certamente pode ser usado durante o processamento da leitura).

Figura 5 - No ritmo das palavras

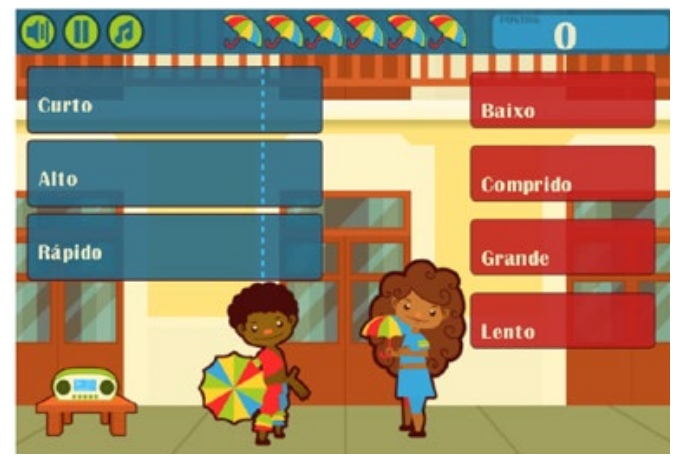

Fonte: NO RITMO DAS PALAVRAS, s. d.

Na Figura 5, o jogador deve associar sinônimos se as roupas dos dois personagens são da mesma cor e associar antônimos se elas forem de cores diferentes. Agrupar palavras pelo critério de aproximação de sentido (sinonímia) e separar palavras pelo critério de oposição de sentido (antonímia) é uma habilidade relevante para os estudos semânticos, o problema é que a atividade para isso ocorre por meio de listas de palavras descontextualizadas.
Figura 6 - Game da Reforma Ortográfica

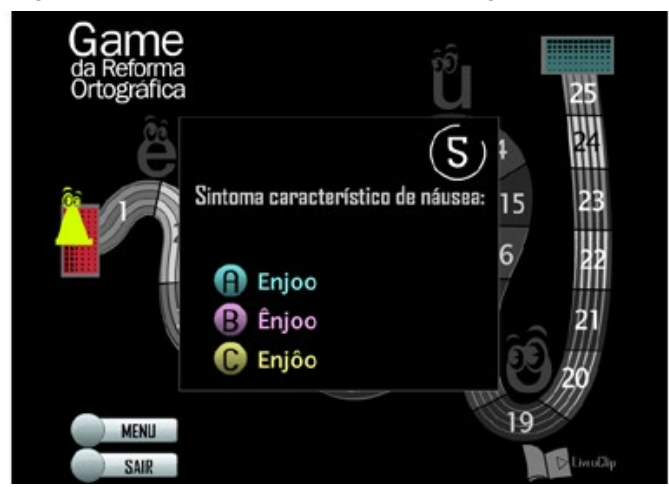

Fonte: GAME DA REFORMA ORTOGRÁFICA, s. d.

O "Game da Reforma Ortográfica" (Figura 6) apresenta um tabuleiro marcado por um caminho de casas entre início e fim e o jogador só consegue avançá-las à medida que acerta a grafia das palavras. Não se trata de um game, como vimos neste trabalho, mas de uma atividade de perguntas e respostas que poderia ser dada no papel convertida em flash para ter um visual bonito, atraente e lúdico.

Figura 7 - ????

Sopa de

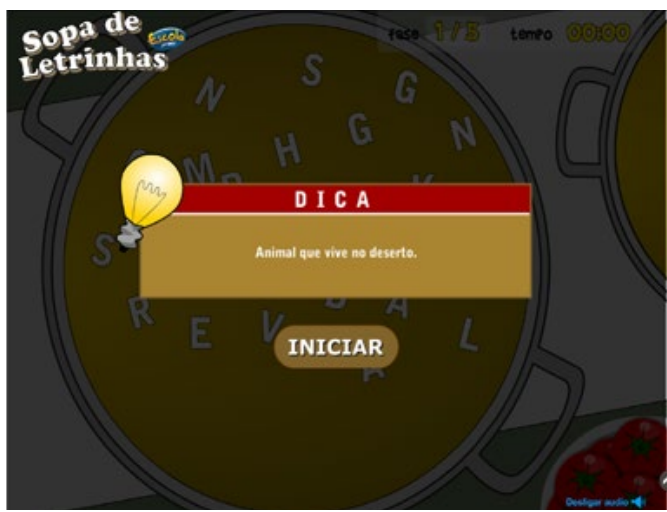

Fonte: NA TRILHA DO SACI, s. d. 
Figura 8: (continuação) Sopa de letrinhas

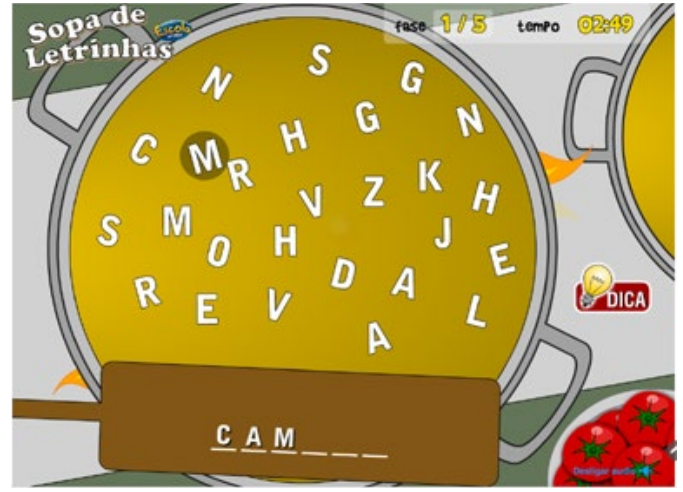

Fonte: SOPA DE LETRINHAS, s. d.

Figura 9 - Na Trilha do Saci

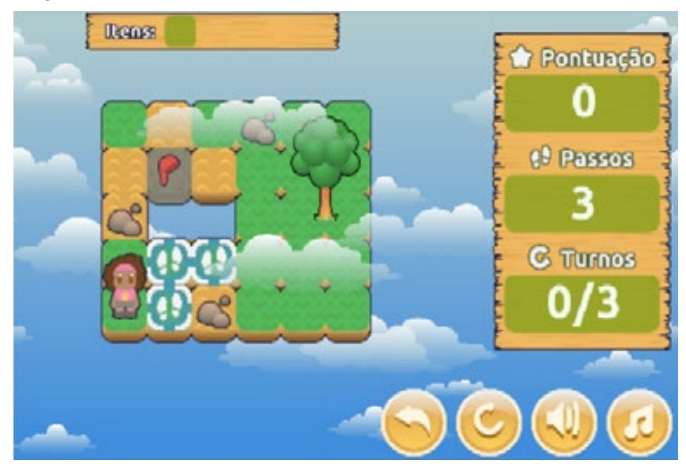

Fonte: NA TRILHA DO SACl, s. d.

Figura 10 - (continuação) Na Trilha do Saci

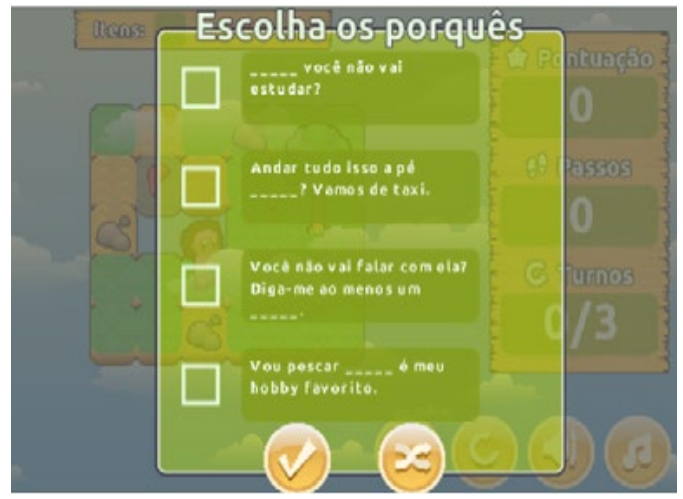

Fonte: NA TRILHA DO SACl, s. d
O mesmo acontece com os jogos "Sopa de letrinhas" (Figuras 7 e 8) e "Na trilha do saci" (Figuras 9 e 10). No primeiro, antes de formar a palavra, o jogador precisa imaginar sua grafia e segmentá-la adequadamente. Trata-se de uma habilidade prevista na BNCC (BRASIL, 2017) para estudantes de $1^{\circ}$ e $2^{\circ}$ anos como prática de escrita (compartilhada e autônoma) e como análise linguística/ semiótica apropriada para alfabetização. Já o segundo se propõe a apresentar um personagem jogável, o que já corresponde ao design de game definido por Gee (2004). Porém, conforme o jogador o move, abrem-se telas para que sejam completados os espaços em branco das frases corretamente com um dos quatro porquês da língua portuguesa.

Além desses exemplos, tivemos acesso ainda ao game "Life is strange", do gênero aventura lançado em 2015. Aguiar (2017) constatou que o fato de, no jogo, haver um movimento temporal constante pelo qual passa a personagem principal (ela experimenta ações e suas implicações no passado, no presente e no futuro), pode favorecer, por exemplo, atividades que trabalhem os tempos verbais, gêneros próprios do contexto da cultura gamer, além de vários gêneros textuais, como e-mail, mensagem de texto (celular), cartaz, músicas e timeline de redes sociais, os quais podem motivar o trabalho com a escrita e com a oralidade (AGUIAR, 2017). 
Figura 11 - Imagens do game "Life is strange"

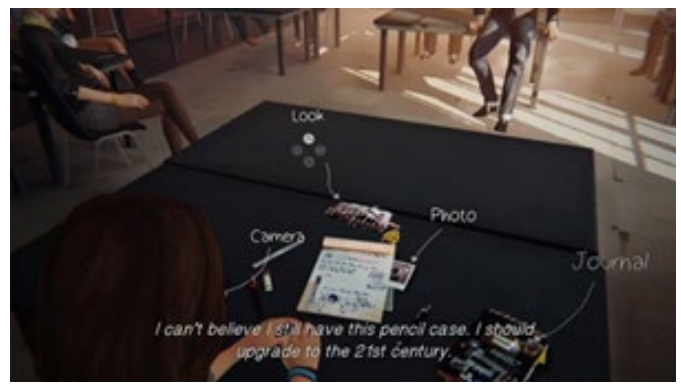

Fonte: TRACE EFFECTS, 2012.

Ainda no ensino de língua, temos outro exemplo, o game "Trace Effects". Conforme informações da página eletrônica que hospeda o jogo, trata-se de uma experiência colaborativa de videogame

Figura 12 - Imagens do game "Face Effects"

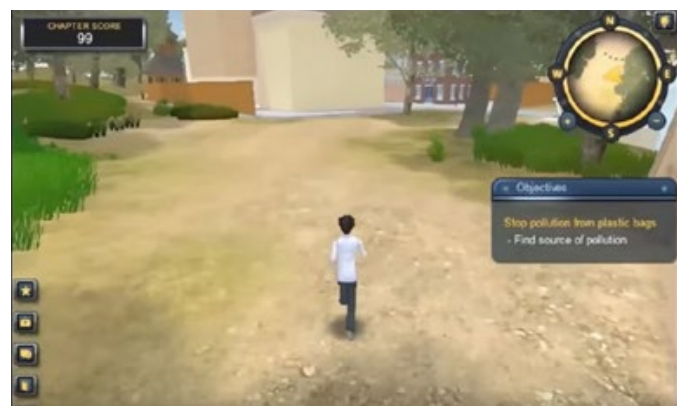

Fonte: do autor.

"Trace Effects" foi utilizado por Souza et al. (2015) em aulas de língua inglesa para estudantes brasileiros do Ensino Médio. Elas revelaram que os alunos tendem a se tornar envolvidos quando jogam, mas devem ser sempre lembrados da finalidade educativa do jogo, independente de notas na escola ou pontos no game. As pesquisadoras concordam que as atividades escolares devem permitir

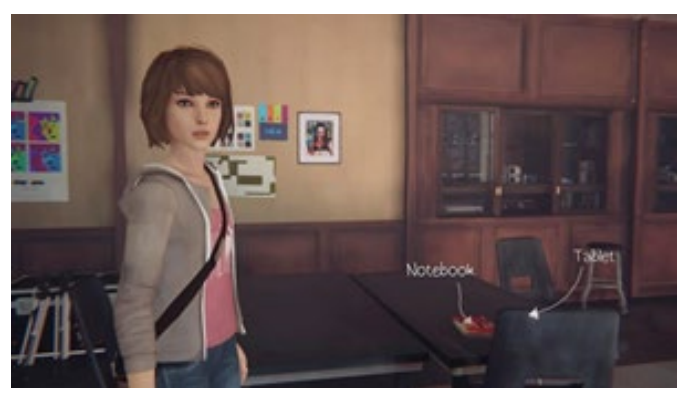

em inglês para alunos de 12 a 16 anos para aprender a língua e explorar a cultura americana através de quebra-cabeças, jogos e aventuras em um mundo interativo.

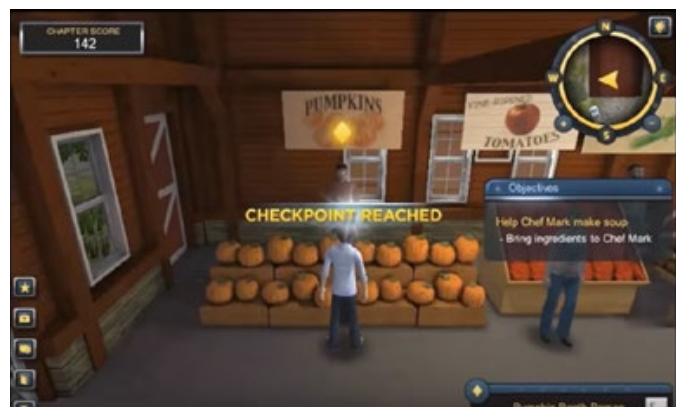

aos alunos trabalharem em seu próprio ritmo e se beneficiarem tanto quanto puderem do que já sabem e do que estão aprendendo. Para isso, defendem os jogos como uma trajetória interessante e frutífera a seguir; sendo necessário, obviamente, todo um planejamento para que o conhecimento adquirido por meio deles possa ser consolidado. 
De todos os games acessados, recomendamos "Scribblenauts Unlimited" para o aprendizado de palavras (englobando léxico, semântica, morfologia e ortografia). Trata-se de um jogo de ação e aventura em que não há uma ordem definida de ações e objetivos (conferindo maior liberdade ao jogador).

Figura 13 - Imagens do jogo "Scribblenauts Unlimited"
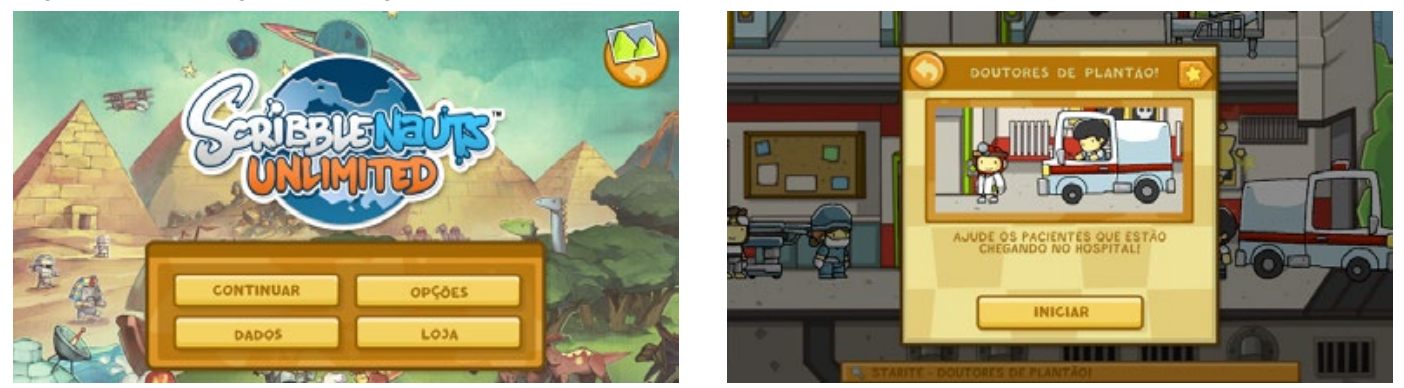

Fonte: (SCRIBBLENAUTS UNLIMITED, 2012).

Ele traz no início explicações sobre palavras em criações tangíveis. Por como usar as palavras para criar objetos exemplo, se um personagem pedir ajuda e designar adjetivos, resolvendo com eles os problemas propostos. Seu personagem principal, Maxwell, deve coletar Starites (estrelas) para libertar sua irmã de uma maldição $0^{3}$. Para conseguir isso, ele terá que ajudar as pessoas a resolver seus problemas, tendo um caderno mágico com o qual o jogador pode transformar mostrando seu gato doente, o jogador pode abrir seu caderno mágico e escrever "remédio" para obter um medicamento que possa curar o animal, ou o que lhe vier à cabeça que tenha essa propriedade de cura, fazendo uso de todo conhecimento adquirido e da bagagem semântica e lexical (veja o exemplo na Figura 13). 
Figura 14 - Exemplo de missão do jogo "Scribblenauts Unlimited"
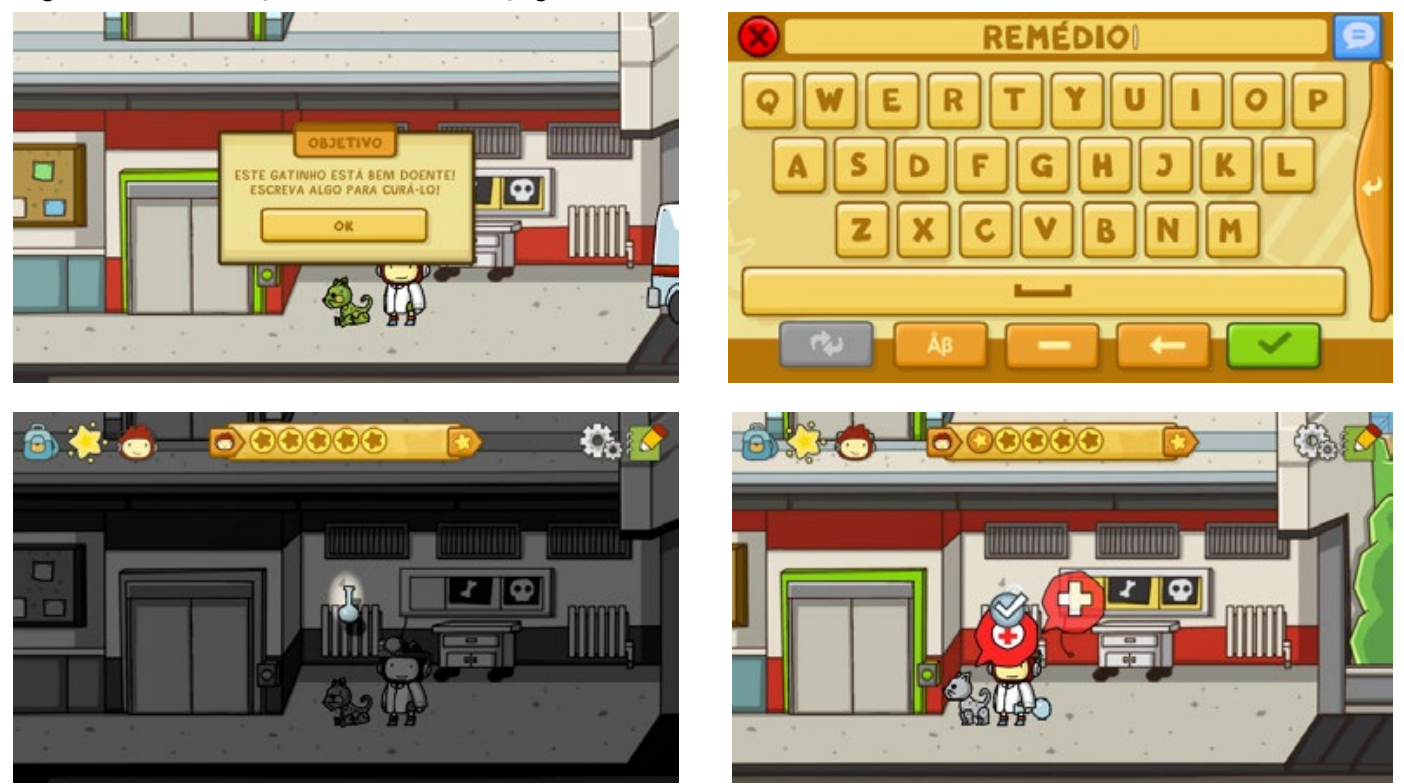

Fonte: do autor

Testamos outras palavras para verificar as reações aos objetos criados. Alcançamos o objetivo dessa pequena missão (curar o gato doente), oferecendo 'soro' ao animal ou chamando um 'veterinário', como pode ser visto na Figura 14. Quando escrevemos 'veneno' e demos o objeto criado ao gato, surgiu na tela a mensagem "Um aliado foi derrotado", com as opções de repetir a missão ou sair dela. Logo, percebemos que não é qualquer palavra que corresponderá ao sucesso do objetivo. 
Figura 15 - Possibilidades de cumprimento da missão do jogo "Scribblenauts Unlimited"
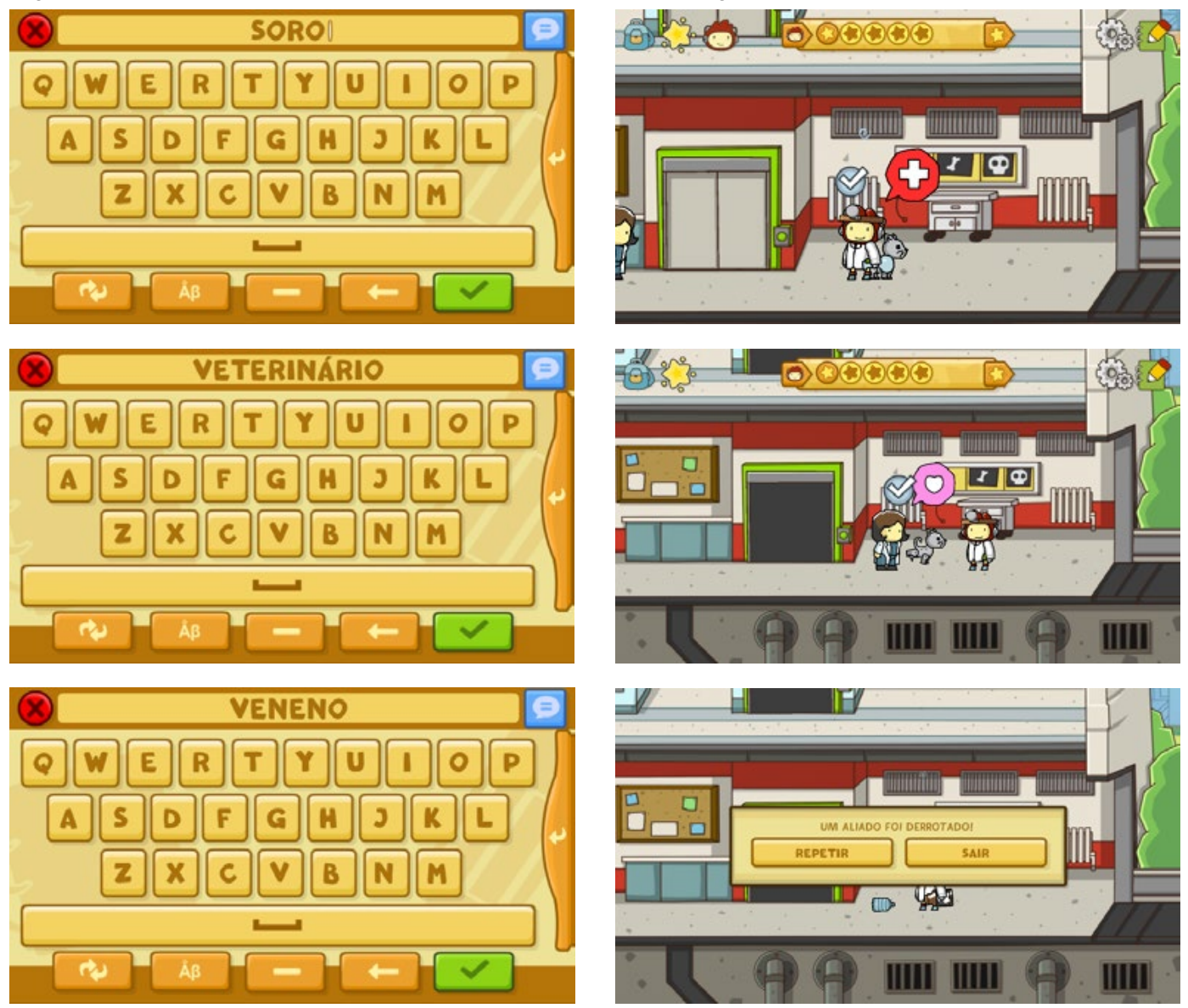

Fonte: do autor

Apesar de serem imaginários e irreais, o jogo permite resolver situações por meio da sua própria cultura, conhecimento de mundo e criatividade. É necessário o desenvolvimento da capacidade lógica para ter que interpretar os objetivos e alcançá-los, precisando sempre da criação de um objeto ou de um adjetivo que solucionará uma demanda. Isso faz com que o jogador esteja sempre escrevendo as palavras

e adequando variados sentidos para atender a cada situação, possibilitando o desenvolvimento do seu léxico.

Além disso, caso não saiba a grafia correta da palavra que pretende utilizar, o game apresenta uma lista de palavras semelhantes às escritas, o que faz $o$ jogador pensar sobre a grafia do termo que ele vai usar e seus parônimos, um aspecto que lhe permitirá enriquecer seu 
vocabulário. Na Figura 15, por exemplo, ao escrever 'dentista', o game disponibi- liza o sentido referente ao consultório ou ao profissional.

Figura 16 - Exemplo de missão do jogo "Scribblenauts Unlimited" com sentidos diferentes
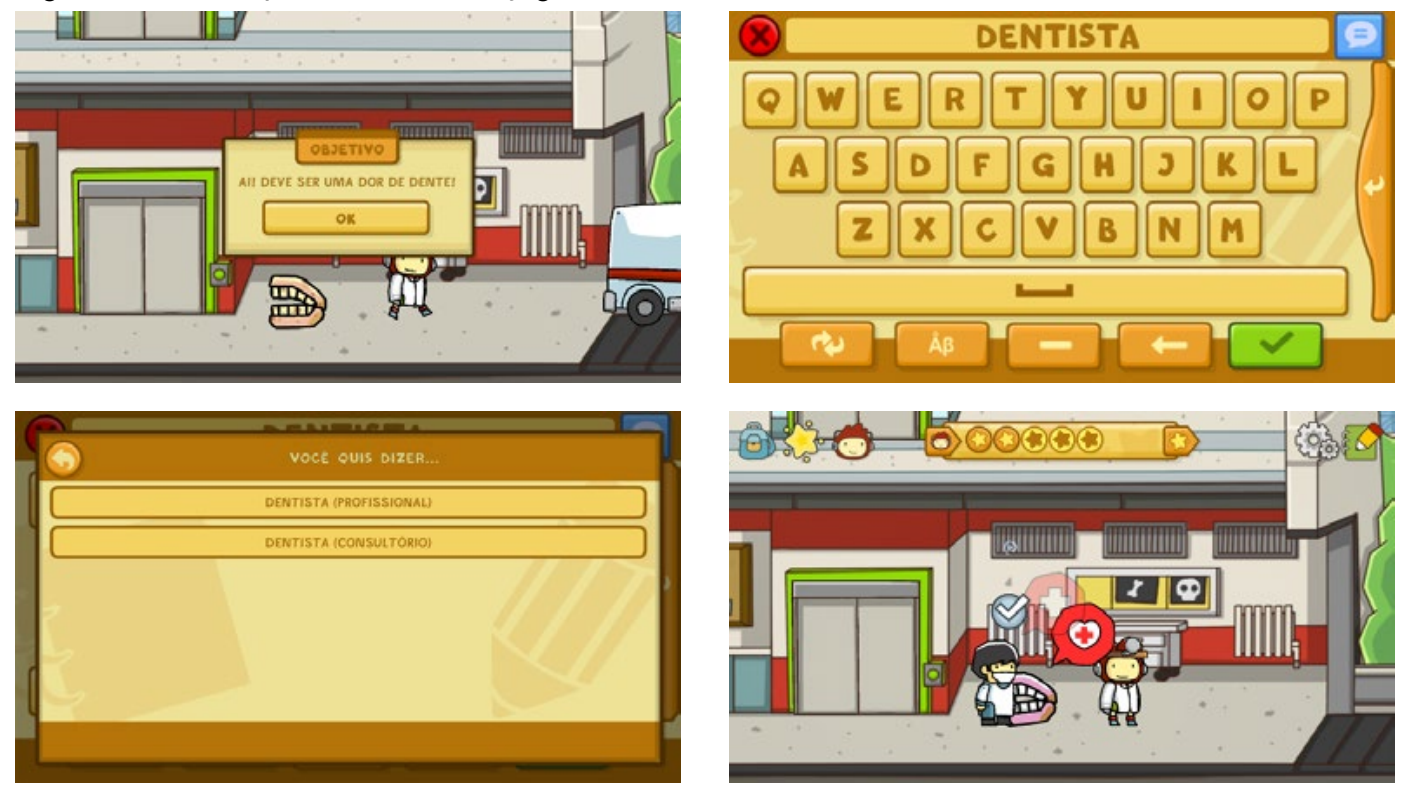

Fonte: do autor.

$\mathrm{Na}$ base de dados do Portal de Periódicos da Capes ${ }^{4}$ obtivemos 1.850 resultados para os termos 'gamification' e 'language', sendo que apenas 5 são específicos para o ensino de língua portuguesa. No Google Acadêmico, conseguimos 18.700 resultados, porém quando alteramos a busca para não exibir respostas que contenham 'foreign', 'second' ou 'L2', temos o número de 3.770 resultados, cinco vezes menor. Ao buscar pelas palavras em português, temos 608 resultados. Ou seja, diferente de quando procuramos produções acadêmicas sobre jogos digitais e ensino de língua, em que

o maior número se concentra com inglês como segunda língua/língua estrangeira, ao pesquisarmos sobre português como língua materna, os resultados são cada vez menores.

O mesmo acontece na relação do game 'Scribblenauts' e 'língua'/language'. Encontramos produções acadêmicas com pesquisas sobre o jogo específico em outras línguas, como no aprendizado de léxico e ortografia francesa na educação superior (BRAZO MILAN et al., 2018) e no desenvolvimento de habilidades de leitura de alunos de sete a nove anos da educação básica de uma escola estadu- 
nidense (PARKER, 2015). Em contexto brasileiro, percebemos o uso do jogo com Campos, Oliveira e Brawerman-Albini (2013) também para o ensino de língua estrangeira, neste caso, o inglês.

Almeida (2015) enumera alguns pontos positivos para o uso desse game em contextos educacionais: 1 ) pode ser utilizado no processo de alfabetização por reconhecer mais de 22 mil palavras; 2) apresenta opções aproximadas, ao digitar alguma letra que não pertence à grafia adequada de uma palavra; 3 ) oferece possibilidade de ensino de várias línguas, pois tem suporte para inglês, francês, espanhol, holandês, alemão, italiano e o português; 4) desafia os jogadores a resolverem o mesmo desafio de maneiras diferentes e conectar objetos na criação de ferramentas complexas; 5) pode ser aplicado por meio de projetos educacionais ou em contextos de aprendizagem informal.

Corroboramos com Lee e Hammer (2011) que o potencial da gamificação vai além de promover estilos de vida saudáveis e estratégias de marketing. Os jogadores voluntariamente investem inúmeras horas no desenvolvimento de suas habilidades de resolução de problemas no contexto dos jogos (GEE, 2008). Eles reconhecem o valor da prática estendida e desenvolvem qualidades pessoais, como persistência, criatividade e resiliência através do jogo prolongado. A gamificação tenta aproveitar o poder motivacional dos jogos e aplicá-lo aos problemas do mundo real. Borges (2013), apoiado nas ideias de Gee (2004), defende que as necessidades de aprendizagem que o jogo requer para que o jogador vença os desafios é que contribui para proporcionar entretenimento e, consequentemente, a repetibilidade, o desejo de o jogador permanecer continuamente jogando no ambiente.

Gee (2004) alerta que os desenvolvedores de jogos educativos têm muito que aprender com os desenvolvedores de jogos da indústria do entretenimento. Uma observação que se faz sobre os jogos educacionais é que eles, muitas vezes, são vistos pelas crianças como tarefas. Isso porque eles exigem da criança um conhecimento prévio sobre a aprendizagem do conteúdo formal da escola que é trabalhado no jogo como instruções explícitas. Embora contribuam para a aprendizagem e sejam considerados mais agradáveis do que as tarefas tradicionais, falta aos jogos educacionais a repetibilidade que os jogos de entretenimento possuem.

No entanto, acredita-se que o jogo pode divertir e proporcionar aprendizagem de conteúdos que são pertinentes para a formação escolar, despertando o interesse da criança em jogá-lo, independentemente da vontade de professores e pais. Se os jogos educacionais forem utilizados, fora do espaço escolar, com um alto grau de repetibilidade poderia até 
se pensar em serem incorporados pela indústria do entretenimento como um diferencial e um atrativo para as vendas. Para isso, é preciso conhecer mais sobre como requerer aprendizagens que tornem os desafios instigantes e atrativos para que o jogador se divirta.

\section{Conclusão}

Quando pensamos em jogos digitais para o ensino de línguas, Leffa, Bohn, Damasceno, Marzari (2012) afirma que estamos propondo transformar o lazer, que é a finalidade do jogo, em um meio para um fim diferente, que é a aquisição da língua.

No exemplo dado por Leffa, Bohn, Damasceno, Marzari (2012), com o game "World of Warcraft", quem jogasse por diversão optaria pela versão traduzida do jogo; quem jogasse para aprender inglês escolheria a versão original, não sendo um aprendizado incidental.

No caso da aprendizagem de uma segunda língua por meio do jogo digital, o aluno precisa desejar e ter como objetivo esse aprendizado, transformando o que é lazer, que é o jogo, em um instrumento de mediação para chegar ao seu objetivo.

No entanto, nosso principal foco é mostrar que, de todos os games analisados, "Scribblenauts" permite ao jogador utilizar a língua para se expressar e partilhar informações, experiências, ideias e sentimentos em diferentes contextos e produzir sentidos que levem à resolução dos desafios propostos e aprimorar os conhecimentos grafofônicos, ortográficos, lexicais, morfológicos e semânticos que operam nas análises linguísticas e semióticas necessárias à compreensão e à produção de linguagens, lembrando que essa habilidade precisa ser concomitantemente construída a partir do $1^{\circ}$ ano do Ensino Fundamental.

Com a finalidade de nos aprofundar sobre $o$ assunto, procuramos e testamos jogos digitais gratuitos que se propõem a ensinar palavras e sentidos e os analisamos, relacionando fatores que contribuem para o aprofundamento de uma dimensão mais importante do estudo do léxico e da relação entre a língua e a existência do falante ao contrário de aspectos formais secundários de ordem meramente sistêmica.

\section{Gamification and lexicon teaching in Portuguese language learning}

\section{Abstract}

Following the assumptions of Gee (2003, 2004, 2005 and 2014), we argue that digital games can become a powerful teaching tool than one language, and this work will deal with Portuguese as their mother tongue and the words and senses education. First, we deal with as is the teaching of the lexicon in basic education classroom, here encompassing words and senses. Then we treat the use of di- 
gital games as teaching tools. We selected a few games and we exposed its technical aspects and mechanis$\mathrm{ms}$, such as layout, interactivity, fun and gameplay. We conducted a relationship between these aspects to the elements that characterize them as an educational tool. In order to delve on the subject, we try and test free digital games that purport to teach words and meanings and analyze them, relating factors that contribute to the deepening of a more important aspect of the study of the lexicon and the relationship between language and the existence of the speaker as opposed to secondary formal aspects of purely systemic order. Of all the analyzed games, Scribblenauts allows the player to use language to express and share information, experiences, ideas and feelings in different contexts and produce meanings.

Keywords: Digital games. Gamification. Teaching of the lexicon. Language teaching. Portuguese teaching.

\section{Notas}

1 Neste artigo, trataremos como sinônimos jogos digitais, jogos eletrônicos e games.

2 Este game pode ser encontrado em https:// americanenglish.state.gov/trace-effects. Acesso em: 10 ago. 2018.

3 Informações disponíveis em https://en.wikipedia. org/wiki/Scribblenauts_Unlimited, acesso em 8 ago 2018.

4 Disponível em: http://www-periodicos-capes-gov-br.ez37.periodicos.capes.gov.br/index. php?option\%3Dcom_phome\%26Itemid\%3D68\%26. Acesso em: 1 set. 2018.

\section{Referências}

AGUIAR, A.P.S. Jogos eletrônicos e ensino de língua portuguesa: algumas reflexões. Texto Livre, v. 10, p. 1-17, 2017.

AMEIDA, F. N. Jogo aplicado à educação. Experiência escolar com Ensino Fundamental II. Dissertação (Mestrado em Tecnologias da Inteligência e Design Digital) - Pontifícia Universidade Católica de São Paulo, 2015.

BIDERMAN, M. T. C. Léxico e vocabulário fundamental. Alfa, v. 40, p. 27-46, 1996.

BORGES, A. P. Jogo digital para reconhecimento de palavras: análise comparativa entre as versões com instruções implícitas e explícitas. 2013. 163 f. Tese (Doutorado em Estudos Linguísticos) - Faculdade de Letras, Universidade Federal de Minas Gerais, Belo Horizonte.

BRASIL. Base Nacional Comum Curricular. Brasília: MEC, 2017. Disponível em: <http:// basenacionalcomum.mec.gov.br/>. Acesso em: 11 set. 2017.

BRASIL. Ministério da Educação. Secretaria da Educação Fundamental. Parâmetros Curriculares Nacionais: $5^{\mathrm{a}}$ a $8^{\mathrm{a}}$ série do Ensino Fundamental - Língua Portuguesa. Brasília: MEC/SEF, 1998.

BRASIL. Ministério da Educação. Secretaria de Educação Média e Tecnológica Semtec. Parâmetros Curriculares Nacionais para o Ensino Médio: Parte II - Linguagens Códigos e suas Tecnologias. Brasília: MEC/Semtec, 2002.

BRAZO MILLÁN, A.I., GONZÁLEZ, J.M.M; CASTRO, C.C. Aprendiendo léxico y ortografía francesa en la universidad mediante el videojuego SCRIBBLENAUTS. Revista Edmetic. v. 7, n. 2, 2018.

CAMPOS, M. S.; OLIVEIRA, K. S. ; BRAWERMAN-ALBINI, A. The use of videogames in the teaching-learning process of 
English as a foreign language. In: INTERNATIONAL CONFERENCE OF INTERACTIVE COMPUTER AIDED BLENDED LEARNING, 2013, Florianópolis. Anais do ICBL 2013, 2013. p. 218-223.

DELL'ISOLA, R. L. P. O sentido das palavras na interação leitor $<->$ texto. Belo Horizonte: Faculdade de Letras da UFMG, 2005.

FREGONEZI, D. E. A formação permanente do professor de língua portuguesa. In: SEMINÁRIO DO GEL- GRUPO DE ESTUDOS LINGÜÍSTICOS DO ESTADO DE SÃO PAULO, 1994, São Paulo. XXIII Anais de Seminários do GEL. São Paulo/SP: Editora da Univ. de São Paulo, 1994. p. 705-711.

GAME DA REFORMA ORTOGRÁFICA. Livro Clip. São Paulo: Complexo Educacional FMU, s. d. Disponível em: http://www. livroclip.com.br/livrogames/games/fmu/fmu. html. Acesso em 8 ago. 2018.

GEE, J. P. 13 Principles of Game-based Learning, Video Games and Learning. Coursera, Mountain View, CA, 2014.

GEE, J. P. Learning and games. In: Katie Salen (Ed.) The ecology of games: Connecting youth, games, and learning (John D. and Catherine T. MacArthur Foundation series on digital media and learning). Cambridge, MA: The MIT Press, 2008.

GEE, J. P. Situated language and learning: a critique of traditional schooling. London: Routledge, 2004.

GEE, J. P. What video games have to teach us about learning and literacy. New York: Palgrave/Macmillan, 2003.

GEE, J. P. Why video games are good for your soul: pleasure and learning. Melbourne: Common Ground, 2005.

GODWIN-JONES, R. Augmented reality and language learning: From annotated vocabulary to place-based mobile games. Language Learning \& Technology, v. 20, n. 3, p. 9-19, 2016.
JOGO DOS ADVÉRBIOS. Só Português. Porto Alegre: Virtuous Tecnologia da Informação, s. d. Disponível em: https://www.soportugues.com.br/secoes/jogos.php\#. Acesso em: 8 ago. 2018.

JOGO DOS SUBSTANTIVOS. Só Português. Porto Alegre: Virtuous Tecnologia da Informação, s. d. Disponível em: https://www. soportugues.com.br/secoes/jogos.php\#. Acesso em: 8 ago. 2018.

KAPP, K. M. The Gamification of learning and instruction: Game-based methods and strategies for training and education. Pfeiffer. Hoboken, NJ, 2012.

LAUFER, B. 1997 The lexical plight in second language reading. IN: COADY, J. \& T.N. HUCKIN 1997. Second Language Vocabulary Acquisition. Cambridge University Press. p. 20-34.

LEE, J. J.; HAMMER, J. Gamification in education: what, how, Why Bother? Definitions and uses Exchange Organizational Behavior Teaching Journal, 15 (2), 2011, p. 1-5.

LEFFA, V. J.; BOHN, H. I.; DAMASCENO, V. D.; MARZARI, G. Q. Quando jogar é aprender: o videogame na sala de aula. Revista de Estudos da Linguagem, v. 20, p. 209-230, 2012.

LIFE IS STRANGE. Paris: Dontnod Entertainment, 2015.

LISKA, G. J. R. O estudo do léxico na sala de aula: investigação do ensino dos processos semânticos de formação de palavras sob a perspectiva da Semântica de Contextos e Cenários (SCC). Belo Horizonte: UFMG, 2018. 265 p. Tese (Doutorado) - Programa de Pós-Graduação em Estudos Linguísticos da Faculdade de Letras da Universidade Federal de Minas Gerais, Belo Horizonte, 2018.

LISKA, G. J. R. O humor da palavra e o desenvolvimento da competência lexical: análise de livros didáticos de português dos anos finais do ensino fundamental. Belo 
Horizonte: UFMG, 2013. 201 p. Dissertação (Mestrado) - Programa de Pós-Graduação em Estudos Linguísticos da Faculdade de Letras da Universidade Federal de Minas Gerais, Belo Horizonte, 2013.

NA TRILHA DO SACI. Ludo Educativo. Direitos reservados à CNPq e FAPESP. São Paulo: Aptor Software, s. d. Disponível em: https://www.ludoeducativo.com.br/pt/games. Acesso em: 8 ago. 2018.

NO RITMO DAS PALAVRAS. Ludo Educativo. Direitos reservados à CNPq e FAPESP. São Paulo: Aptor Software, s. d. Disponível em: https://www.ludoeducativo.com.br/pt/ games. Acesso em: 8 ago. 2018.

OSTERWEIL, S.; LE, L. X. Learning and change: a view from MIT's Education Arcade. The International Journal Cognitive Techno$\log y$, v. 14, n. 2, p. 58-65, 2010.

PALAVRAS COMPLICADAS. Só Português. Porto Alegre: Virtuous Tecnologia da Informação, s. d. Disponível em: https://www.soportugues.com.br/secoes/jogaos.php\#. Acesso em: 8 ago. 2018.

PARKER, N. D. Utilizing SCRIBBLENAUTS to increase reading comprehension and improve literacy skills of third grade students. (Doctoral Dissertation) East Carolina University, 2015.

RICHARDS, J. The role of vocabulary teaching. TESOL Quarterly, v. 10, n. 1, 1976.

SCRIBBLENAUTS UNLIMITED. Bellevue, WA: 5th Cell, 2012.

SEGUINDO A LÓGICA. Só Português. Porto Alegre: Virtuous Tecnologia da Informação, s. d. Disponível em: https://www.soportugues. com.br/secoes/jogos.php\#. Acesso em: 8 ago. 2018.

SOPA DE LETRINHAS. Escola Games. Uberlândia: Núcleo Tecnologia da informação Ltda, s. d. Disponível em http://www. escolagames.com.br/. Acesso em: 8 ago. 2018.
SOUZA, V. V. S.; REIS, I. A. R.; OLIVEIRA, S. A. S. Playing Trace Effects with brazilian high school students: complexity and games. Revista Desempenho, v. 14, p. 1-21, 2015.

TRACE EFFECTS. Bureau of Educational and Cultural Affairs. Washington, D.C: U.S. State Department, 2012. Disponível em: https:/americanenglish.state.gov/trace-effects. Acesso em: 8 ago. 2019. 